\title{
Evaluation of grain breakage sensitivity of maize varieties mechanically-harvested by combine harvester
}

\author{
Yizhou Wang, Lulu Li, Shang Gao, Yanan Guo, Guoqiang Zhang, Bo Ming, Ruizhi Xie, \\ Jun Xue, Peng Hou, Keru Wang, Shaokun Li* \\ (Institute of Crop Sciences, Chinese Academy of Agricultural Sciences, Key Laboratory of Crop Physiology and Ecology, Ministry of \\ Agriculture and Rural Affairs, Beijing 100081, China)
}

\begin{abstract}
A high grain breakage rate is the main problem that occurs during mechanical maize harvest in China. The breakage sensitivity of different varieties was significantly different, and the breakage resistance is heritable. Therefore, breakage resistant variety screening can help improve the field production efficiency and provide references for breeding work. In this study, 42 varieties of maize were harvested with the same mechanical parameters and the same manipulator on a range of harvest dates at experimental stations in Xinxiang, Henan Province, in 2017 and Changji, Xinjiang Province, in 2018 to determine the sensitivity of grain moisture content on grain breakage rate during machine harvest for different varieties. The integral value of the grain breakage rate curve corresponding to the range of $15 \%$ to $30 \%$ grain moisture content was used as an index that expressed the sensitivity of maize grains to breakage depending on grain moisture content (BSW). Forty-two varieties were categorized as having weak, intermediate, or strong BSW. Among the same four varieties in the two stations, Lianchuang 825 and Lianchuang 808 were classified as sensitive and fragile varieties, Shandan 650 was classified as an intermediate variety, Zeyu 8911 was divided into weak sensitive and breakage-resistance varieties in Xinxiang and intermediate varieties in Changji. The BSW classification results at the two experimental sites were generally consistent, indicating that breakage sensitivity due to moisture content may be a relatively stable genetic characteristic. This study suggested that the integral method for determining BSW can be used to assess the resistance of different maize varieties to grain breakage during mechanical harvesting. The integral method was used to identify twelve breakage-resistant varieties in Xinxiang Station, and six breakage-resistant varieties in Changji Station. This study provides a method for screening maize varieties that are suited to mechanical grain harvesting and for studying the mechanisms of grain breakage resistance.
\end{abstract}

Keywords: maize, mechanical grain harvest, breakage resistance, integral method, varieties classification DOI: $10.25165 / j . i j a b e .20201305 .6037$

Citation: Wang Y Z, Li L L, Gao S, Guo Y N, Zhang G Q, Ming B, et al. Evaluation of grain breakage sensitivity of maize varieties mechanically-harvested by combine harvester. Int J Agric \& Biol Eng, 2020; 13(5): 8-16.

\section{Introduction}

Modern maize production in China is progressing toward complete mechanization, but mechanized harvesting, especially grain harvesting, currently presents a bottleneck in the production process $^{[1-4]}$. Grain breakage rate is an important indicator of the

\section{Received date: 2020-07-24 Accepted date: 2020-09-12}

Biographies: Yizhou Wang, Master, research interest: grain breakage sensitivity of maize, Email: 929589071@qq.com; Lulu Li, PhD candidate, research interest: maize grain dehydration, Email: lilulu19910818@163.com; Shang Gao, PhD candidate, research interest: maize grain dehydration, Email: g382824817@126.com; Yanan Guo, Master, research interest: grain breakage sensitivity of maize, Email: 1219934377@qq.com; Guoqiang Zhang, PhD, research interest: efficient utilization of maize water and fertilizer, Email: zgq528208@163.com; Bo Ming, PhD, Associate Professor, research interest: efficient utilization of environmental resources in crop production systems, Email: mingbo@caas.cn; Ruizhi Xie, PhD, Professor, research interest: maize physiology and ecology, Email: xieruizhi@caas.cn; Jun Xue, PhD, research interest: maize lodging resistance, Email: xuejun5519@126.com; Peng Hou, $\mathrm{PhD}$, Associate Professor, research interest: physiology and ecology of maize high yield cultivation, Email: houpeng@caas.cn; Keru Wang, PhD, Professor, research interest: theory and technology of maize mechanization production, Email: wangkeru@ caas.cn.

*Corresponding author: Shaokun Li, PhD, Professor, research interest: physiology and ecology of maize high yield and high efficiency cultivation. Institute of Crop Sciences, Chinese Academy of Agricultural Sciences, Beijing 100081, China. Tel: +86-10-82108891, Email: lishaokun@ caas.cn. efficiency of mechanical harvesters ${ }^{[1]}$,and high breakage rates are the main barrier to the implementation of mechanical harvesting techniques $^{[4]}$.

Previous studies have shown that grain breakage rates are affected by factors such as varieties, grain moisture content, environment, cultivation measures and on the type of harvesting machinery used ${ }^{[5-9]}$. Even when the grain moisture content is the same, different maize varieties will experience different breakage rates ${ }^{[10-17]}$ and breakage resistance is heritable ${ }^{[6,17-19]}$. Therefore, breeding breakage-resistant varieties are critical to reducing breakage rates ${ }^{[1]}$.

Many indexes and methods have been developed for determining maize kernel susceptibility to breakage. The breakage susceptibility (BS) index is most widely used and is defined as the likelihood of kernel fragmentation occurring when kernels are subjected to impact forces during handling and transport $^{[20,21]}$. Methods for determining BS can be classified into four categories based on the different external forces applied to grain and contact position. These include grain impacts against non-grain surfaces, grain-on-grain impacts, rubbing impacts, and centrifugal impacts ${ }^{[22,23]}$. The instruments used to determine BS are typically the Wisconsin breakage tester and the Stein breakage tester $^{[24]}$.

In the countries with mature mechanical harvesting technology, the grain moisture content is low during the maize harvest. 
Fragmentation mainly occurs in the handling and transport stage after drying. Therefore, few reports describe direct evaluations of grain breakage resistance in maize hybrids with different grain moisture content in the field harvest period.

A lot of researches show that breakage rates change quadratically with changes in grain moisture content ${ }^{[4,5,17,25]}$. Methods have been proposed for evaluating the grain breakage resistance of different maize varieties using the sum of mean deviations in a quadratic curve of the relationship between grain moisture content and breakage rate ${ }^{[26]}$.

In China, maize mechanical harvesting technology started late, and there are relatively few varieties suitable for mechanical harvesting. It is hoped to establish a method to evaluate the grain breakage resistance of maize hybrids with different water content in the field. Finally, the methods were used to screen for maize varieties that are resistant to grain breakage in order to provide a basis for breeding improved breakage-resistant varieties and investigations into the mechanism of breakage resistance.

\section{Materials and methods}

\subsection{Experimental design}

Field experiments were conducted in 2017 and 2018 at two different locations, one at the Xinxiang Comprehensive Experimental Station of the Chinese Academy of Agricultural Sciences $\left(35^{\circ} 18^{\prime} \mathrm{N}, 113^{\circ} 54^{\prime} \mathrm{E}\right)$ (Xinxiang Station) and the other at the Experimental Demonstration Base of the Western Agricultural

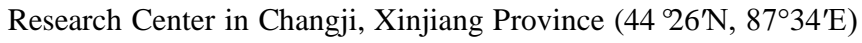

(Changji Station).

In 2017, 28 maize hybrids were selected as experimental materials for Xinxiang Station (Table 1) from among hybrids that were already adapted to the location. Maize was planted on 17-18 June. The planting area for each hybrid was $600 \mathrm{~m}^{2}$ with a $60 \mathrm{~m}$ row spacing and the planting density was 6.7 plants $/ \mathrm{m}^{2}$. Local cultivation and management measurements were adopted. Treatments were harvested on five different dates separated by intervals of 10-15 d: October 6, October 16, October 27, November 10 , and November 25.

In 2018, 18 maize varieties were selected as experimental materials for Changji Station (Table 1) and were planted on April 28-29. The planting area for each hybrid was $600 \mathrm{~m}^{2}$ with $50 \mathrm{~cm}$ row spacing and a length of $100 \mathrm{~m}$. The plant density was 9 plants $/ \mathrm{m}^{2}$. Field management was based on local planting practices. Treatments were harvested on six different dates separated by intervals of 10-15 d: August 28, September 10, September 20, October 2, October 13, and October 20.

The combine harvesters were Futian RevoGuShen GE 50 in Xinxiang station and John Deere W210 in Changji station. The harvest length for each cultivar per harvest period was $20 \mathrm{~m}$ in Xinxiang and $30 \mathrm{~m}$ in Changji. In the same experimental station, the harvesting experiments in different harvesting periods are carried out by using the same harvester with the same mechanical parameters and the same manipulator. The parameters of combine harvester were shown in Table 2.

Table 1 Maize cultivars in this experiment

\begin{tabular}{|c|c|c|c|}
\hline Year & Site and maize season & $\begin{array}{l}\text { Number of } \\
\text { cultivars }\end{array}$ & Maize cultivars \\
\hline 2017 & Xinxiang, summer maize & 28 & $\begin{array}{l}\text { Zhongkeyu 505, Yufeng 303, Lianchuang 808, Nonghua 816, Liaodan 585, Liaodan 586, Liaodan 575, } \\
\text { MC670, Zeyu 501, Zeyu 8911, Jidan 66, Dongdan 913, Lianchuang } 825 \text {, Jintong } 152 \text {, Nonghua 5, } \\
\text { Hengyu 898, Dika 517, Dika 653, Xindan 58, Xindan 65, Xindan } 68 \text {, Shaandan 636, Shaandan 650, } \\
\text { Yuyu 30, Lidan 295, LA505, Beidou 309, Yudan } 9953\end{array}$ \\
\hline 2018 & Changji, spring maize & 18 & $\begin{array}{l}\text { JP6145, Lianchuang 808, Lianchuang 825, KX9384, Xinyu 47, Shandan 650, Fuyu 1512, Shandan } \\
\text { 620, Jiuyu M03, Yuanhua 9, Dongdan 6531, Zeyu 8911, Xianyu 335, Xianyu 1331, KWS2030, } \\
\text { Tieyuan 24, Dongdan 1331, Jiushenhe } 2468\end{array}$ \\
\hline
\end{tabular}

Table 2 Parameters of Futian RevoGuShen GE50 and John Deere W210

\begin{tabular}{lcc}
\hline \multicolumn{1}{c}{ Harvester parameters } & & Harvester model \\
\cline { 2 - 3 } & Futian RevoGushen GE50 & Tohn Deere W210 \\
\hline Threshing and separating system & Tangential flow-Transverse axial flow & Rasp bar cylinder \\
Threshing rotor type & Rasp bar cylinder & $116 \mathrm{~kW} / 158 \mathrm{PS}$ \\
Rated power & $81 \mathrm{~kW} / 1$ 10PS & $7 \mathrm{~kg} / \mathrm{s}$ \\
Feeding quantity & $5 \mathrm{~kg} / \mathrm{s}$ & Tianren \\
Maize header & Xi-ying-ying & Seven-row \\
Cutting range & Four-row & $700 \mathrm{r} / \mathrm{min}$ \\
Drum rotation speed & $700 \mathrm{r} / \mathrm{min}$ & $4 \mathrm{~km} / \mathrm{h}$ \\
Walking velocity & $5 \mathrm{~km} / \mathrm{h}$ & \\
\hline
\end{tabular}

\subsection{Sampling method}

Approximately $2 \mathrm{~kg}$ of grain was collected from the grain tank loading auger after harvesting in each subplot. Grain moisture content was determined using a PM-8188 grain moisture meter immediately after evenly mixing the grain samples; this was repeated five times and the average value was used as the moisture content of the harvested grain for each subplot. Next, $600 \mathrm{~g}$ of grain was weighed and the sample was sorted manually into two parts (Figure 1): grain (designated KW1) and non-seed material (designated NKW). The KW1 sample was subdivided based on the integrity of the grain (breakage grains are defined as those with fragmentation or damaged epidermis by mechanical damage) and weighed separately. The weight of the whole grain was recorded as KW2 and the weight of the broken grain was recorded as BKW. This was repeated three times and the average value was used as the breakage rate of the harvested grain for each subplot. The formula for calculating the rate of grain breakage is as follows:

Grain breakage rate $(\%)=[\mathrm{BKW} /(\mathrm{KW} 2+\mathrm{BKW})] \times 100$

2.3 Evaluation of grain breakage sensitivity to grain moisture content

In China, the moisture content of machine harvesting of maize 
grain is concentrated at $15 \%-30 \%^{[1,2,4]}$. Grain moisture content and the corresponding grain breakage rate of different varieties were fitted to a quadratic curve. The fitting curve of each variety and the area enclosed by $X$-axis in the range of $15 \%-30 \%$ was used to express the susceptibility of maize grains breakage to grain moisture content (BSW). BSW is expressed as the integral value of the quadratic curve in the grain moisture content range of $15 \%-30 \%$ and was calculated as follows:

$$
\mathrm{BSW}=\int_{15}^{30} a x^{2}+b x+c
$$

where, $a, b$, and $c$ are parameters of the fitting equation for different varieties.

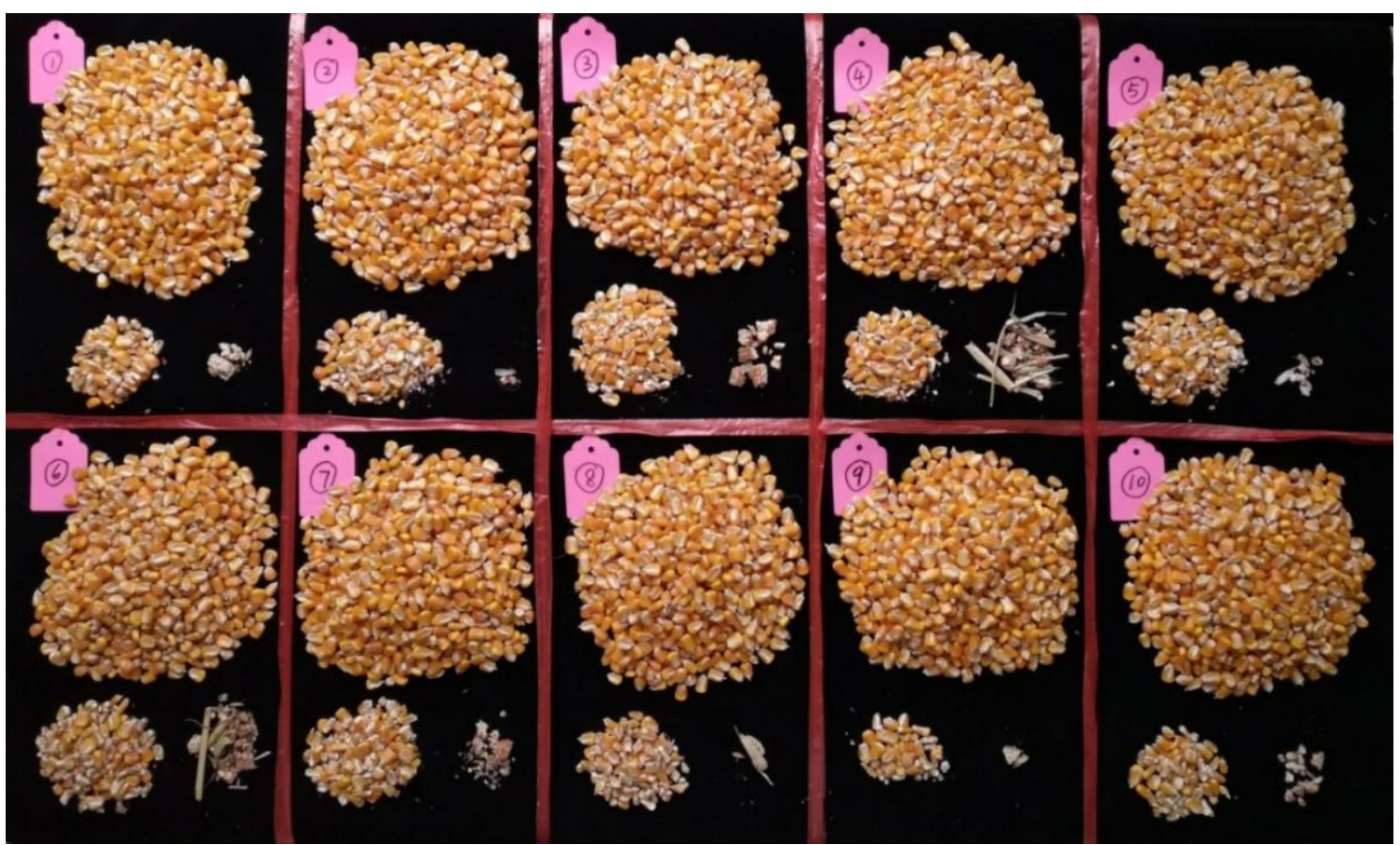

Figure 1 Whole grain, broken grain, and non-seed material

\section{Results}

3.1 Water content and breakage rate of different mechanically-harvested grain varieties

In 2017, 28 maize varieties were harvested from the Xinxiang Station between October 6 and November 25. Grain moisture content ranged from $13.7 \%$ to $43.3 \%$ and the average grain moisture content of the different varieties ranged from 24.8\% (Dika 517) to $30.2 \%$ (Lidan 295). The Nonghua 5 variety displayed the largest variation in grain moisture content across the span of the five different harvest dates $(24.47 \%)$ and the Zeyu 8911 variety displayed the smallest variation $(15.13 \%)$.

The average breakage rate of the different varieties varied from $8.6 \%$ (Zeyu 8911) to $34.9 \%$ (Nonghua 5). The Nonghua 5 variety displayed the largest variation in grain breakage across the span of the five different harvest dates $(31.30 \%)$ and the Zeyu 8911 variety displayed the smallest variation $(5.87 \%)$. Detailed information on each maize variety is shown in Table 3 .

Table 3 Harvested maize kernel moisture content and breakage rate on different dates.

\begin{tabular}{|c|c|c|c|c|c|c|c|c|c|c|c|}
\hline \multirow{3}{*}{ Site } & \multirow{3}{*}{ Cultivar } & \multicolumn{5}{|c|}{ Grain moisture content $/ \%$} & \multicolumn{5}{|c|}{ Grain breakage rate/\% } \\
\hline & & \multicolumn{5}{|c|}{ Harvest date (m-d) } & \multicolumn{5}{|c|}{ Harvest date (m-d) } \\
\hline & & $10 / 5$ & $10 / 16$ & $10 / 26$ & $11 / 10$ & $11 / 25$ & $10 / 5$ & $10 / 16$ & $10 / 26$ & $11 / 10$ & $11 / 25$ \\
\hline \multirow{16}{*}{ Xinxiang } & Liaodan 586 & 38.97 & 35.53 & 28.97 & 23.70 & 19.20 & 14.70 & 18.40 & 6.41 & 4.37 & 7.48 \\
\hline & Liaodan 585 & 41.00 & 37.27 & 30.17 & 21.37 & 18.67 & 29.87 & 21.42 & 9.12 & 2.34 & 6.58 \\
\hline & Liaodan 575 & 41.00 & 35.40 & 29.50 & 22.57 & 18.67 & 24.48 & 20.36 & 7.17 & 4.51 & 9.67 \\
\hline & MC670 & 39.30 & 34.40 & 28.17 & 21.00 & 16.37 & 17.95 & 16.38 & 9.45 & 3.37 & 5.85 \\
\hline & Zeyu 501 & 39.30 & 34.07 & 28.13 & 24.10 & 17.13 & 19.69 & 13.85 & 4.21 & 4.72 & 6.76 \\
\hline & Zеуи 8911 & 33.53 & 32.17 & 26.57 & 20.93 & 18.40 & 8.64 & 6.18 & 2.77 & 3.61 & 5.63 \\
\hline & Jidan 66 & 36.20 & 33.13 & 27.03 & 20.73 & 16.83 & 13.91 & 9.19 & 4.12 & 2.81 & 5.53 \\
\hline & Dongdan 913 & 34.40 & 32.57 & 26.90 & 20.63 & 16.77 & 10.49 & 7.32 & 3.81 & 1.91 & 6.92 \\
\hline & Yufeng 303 & 38.87 & 36.17 & 29.07 & 22.83 & 19.10 & 17.96 & 23.45 & 6.01 & 3.22 & 10.99 \\
\hline & Zhongkeyu 505 & 37.23 & 34.57 & 27.80 & 22.40 & 19.20 & 15.39 & 15.95 & 8.25 & 2.90 & 11.07 \\
\hline & Lianchuang 808 & 40.67 & 31.00 & 28.67 & 22.40 & 20.03 & 27.07 & 13.83 & 8.87 & 3.58 & 10.09 \\
\hline & Lianchuang 825 & 39.97 & 35.13 & 29.70 & 22.80 & 18.33 & 25.99 & 19.90 & 12.14 & 4.76 & 10.35 \\
\hline & Jintong 152 & 43.33 & 35.10 & 28.10 & 20.87 & 18.00 & 28.39 & 15.18 & 10.26 & 2.71 & 12.87 \\
\hline & Nonghua 5 & 42.67 & 36.20 & 27.70 & 21.80 & 17.20 & 34.90 & 22.93 & 10.27 & 3.60 & 11.33 \\
\hline & Nonghua 816 & 42.00 & 35.47 & 28.83 & 22.47 & 18.63 & 32.49 & 25.51 & 12.81 & 3.45 & 8.46 \\
\hline & Hengyu 898 & 38.40 & 32.90 & 25.53 & 20.43 & 15.43 & 19.89 & 10.61 & 4.49 & 2.85 & 8.20 \\
\hline
\end{tabular}




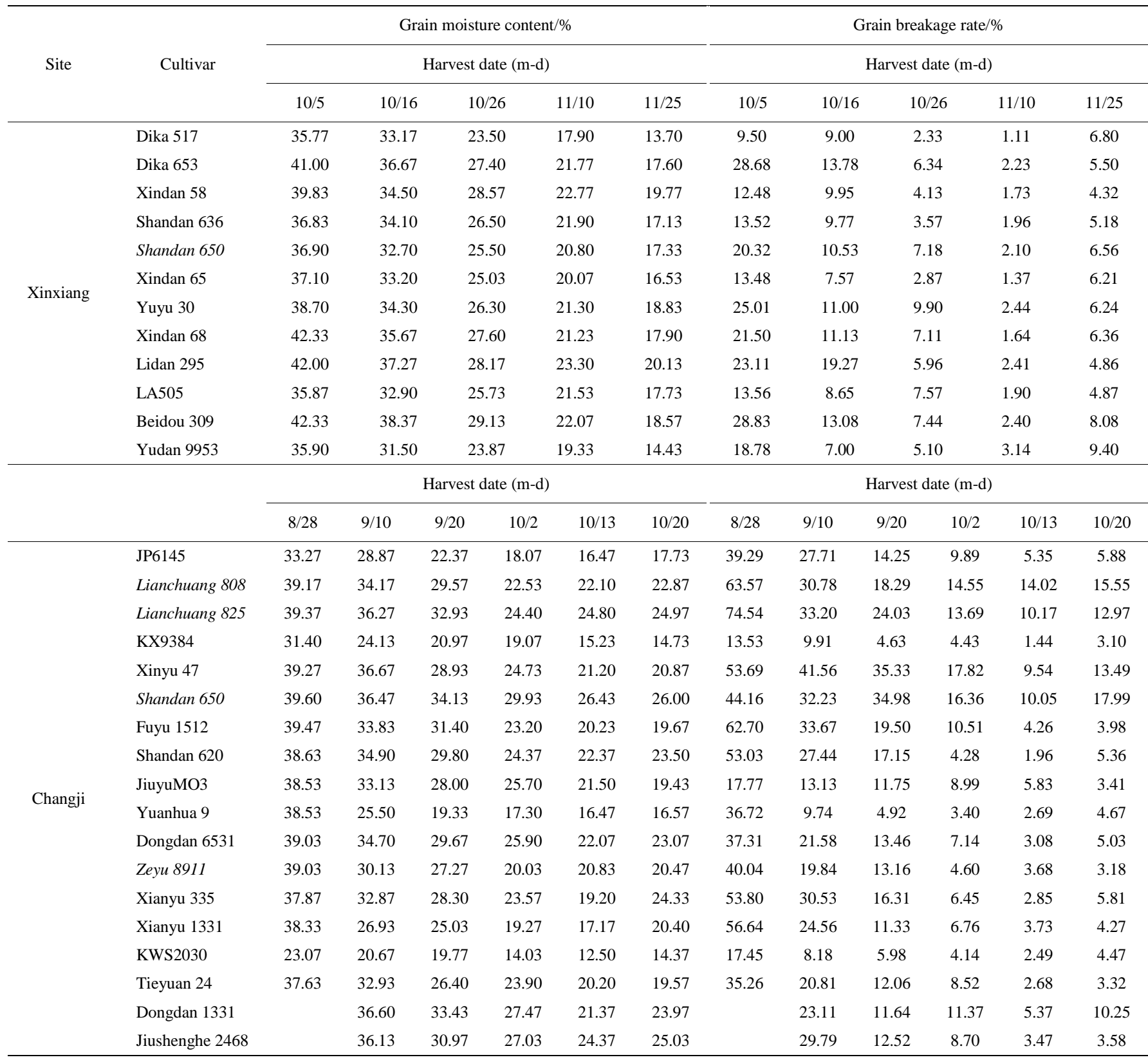

Note: The same maize varieties located in different locations are marked in italics.

In 2018, the 18 maize varieties at Changji Station were harvested between August 28 and October 20. Grain moisture content ranged from $12.5 \%$ to $39.6 \%$ and the average grain moisture content of the different varieties ranged from $17.4 \%$ (KWS2030) to $32.1 \%$ (Shandan 650). Yuanhua 9 variety displayed the largest variation in grain moisture content across the span of the six different harvest dates (22.1\%) and the KWS2030 variety displayed the smallest variation $(10.6 \%)$.

The average breakage rate of the different varieties ranged from $13.5 \%$ (KX9384) to $74.5 \%$ (Lianchuang 825). Lianchuang 825 variety displayed the largest variation in grain breakage across the span of the six different harvest dates (64.4\%) and the KX9384 variety displayed the smallest variation (12.1\%). Detailed information on each maize variety is shown in Table 3 .

3.2 Relationship between grain moisture content and grain breakage rate by maize variety

The relationship between grain moisture content and breakage rate for the samples from the Xinxiang and Changji experimental stations was a quadratic curve. The fitting equation test showed significant levels at the 0.01 level. The fitting equation at
Xinxiang Station was $y=0.061 x^{2}-2.787 x+36.17\left(R^{2}=0.806^{* *}\right.$, $n=140)$ and the equation at Changji Station was $y=0.088 x^{2}-3.042 x+$ $30.80\left(R^{2}=0.794^{* *}, n=106\right)$. The fitting curve for each variety was integrated for the grain moisture content range of 15\%-30\% (Table 4).

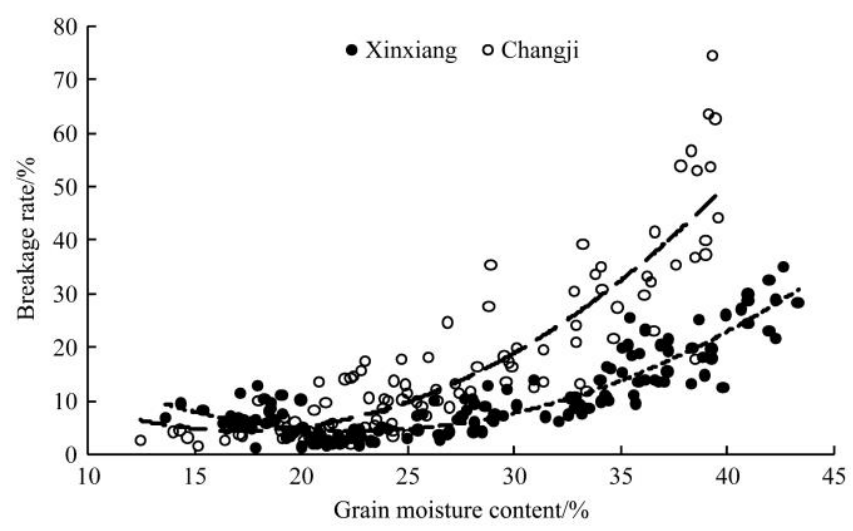

Figure 2 Relationship between the maize grain moisture content and breakage rate 
Table 4 Parameters and integral values of different maize cultivars for the fitting equation $y=a x^{2}+b x+c$, where $y$ is broken rate grain, $x$ is moisture content

\begin{tabular}{|c|c|c|c|c|c|c|}
\hline \multirow{2}{*}{ Site } & \multirow{2}{*}{ Cultivar } & \multicolumn{4}{|c|}{ Parameter } & \multirow{2}{*}{ Integral value } \\
\hline & & $a$ & $b$ & $c$ & $R^{2}$ & \\
\hline \multirow{25}{*}{ Xinxiang } & Liaodan 586 & 0.038 & -1.682 & 24.16 & $0.718 * *$ & 93.975 \\
\hline & Liaodan 585 & 0.076 & -3.45 & 42.95 & $0.988 * *$ & 78.375 \\
\hline & Liaodan 575 & 0.061 & -2.853 & 39.68 & $0.884 * *$ & 112.688 \\
\hline & MC670 & 0.02 & -0.493 & 7.09 & $0.917 * *$ & 97.463 \\
\hline & Zeyu 501 & 0.061 & -2.834 & 37.11 & $0.955 * *$ & 80.55 \\
\hline & Zeyu 8911 & 0.078 & -3.901 & 50.87 & $0.985 * *$ & 60.713 \\
\hline & Jidan 66 & 0.064 & -2.984 & 37.29 & $0.996 * *$ & 56.25 \\
\hline & Dongdan 913 & 0.077 & -3.736 & 47.21 & $0.932 * *$ & 53.625 \\
\hline & Yufeng 303 & 0.085 & -4.286 & 59.31 & $0.706 * *$ & 112.5 \\
\hline & Zhongkeyu 505 & 0.069 & -3.421 & 48.84 & $0.705 * *$ & 121.388 \\
\hline & Lianchuang 825 & 0.06 & -2.662 & 37.19 & $0.936 * *$ & 131.925 \\
\hline & Jintong 152 & 0.056 & -2.664 & 39.23 & $0.876^{* *}$ & 130.35 \\
\hline & Nonghua 5 & 0.068 & -3.016 & 40.88 & $0.957 * *$ & 130.8 \\
\hline & Nonghua 816 & 0.036 & -0.966 & 11.19 & $0.933 * *$ & 125.325 \\
\hline & Hengyu 898 & 0.071 & -3.289 & 41.5 & $0.988 * *$ & 71.587 \\
\hline & Dika 517 & 0.051 & -2.302 & 27.76 & $0.863 * *$ & 41.1 \\
\hline & Dika 653 & 0.079 & -3.722 & 46.56 & $0.963 * *$ & 64.35 \\
\hline & Xindan 58 & 0.029 & -1.246 & 16.38 & $0.911 * *$ & 53.55 \\
\hline & Shandan 636 & 0.061 & -2.873 & 36.07 & $0.991 * *$ & 51.787 \\
\hline & Shandan 650 & 0.072 & -3.24 & 40.12 & $0.929 * *$ & 75.3 \\
\hline & Xindan 65 & 0.067 & -3.205 & 40.17 & $0.960 * *$ & 48.488 \\
\hline & Yuyu 30 & 0.067 & -3.019 & 38.45 & $0.867 * *$ & 85.463 \\
\hline & LA505 & 0.033 & -1.31 & 16.82 & $0.829 * *$ & 70.05 \\
\hline & Beidou 309 & 0.084 & -4.335 & 58.89 & $0.920 * *$ & 81.788 \\
\hline & Yudan 9953 & 0.089 & -4.116 & 50.22 & $0.919 * *$ & 65.025 \\
\hline \multirow{18}{*}{ Changji } & JP6145 & 0.046 & -0.34 & -1.367 & $0.992 * *$ & 226.995 \\
\hline & Lianchuang 808 & 0.269 & -13.71 & 187 & $0.994 * *$ & 296.25 \\
\hline & Lianchuang 825 & 0.504 & -28.29 & 403.8 & $0.965 * *$ & 478.125 \\
\hline & KX9384 & 0.005 & 0.45 & -5.942 & $0.935 * *$ & 102.12 \\
\hline & Xinyu 47 & -0.028 & 3.884 & -57.86 & $0.952 * *$ & 222.45 \\
\hline & Shandan 650 & 0.057 & -1.526 & 13.81 & $0.892 * *$ & 141 \\
\hline & Fuyu 1512 & 0.169 & -7.14 & 80.58 & $0.984 * *$ & 129.825 \\
\hline & Shandan 620 & 0.169 & -7.455 & 85.35 & $0.979 * *$ & 95.063 \\
\hline & JiuyuMO3 & -0.01 & 1.327 & -18.04 & $0.980 * *$ & 98.513 \\
\hline & Yuanhua 9 & 0.061 & -1.898 & 18.12 & $0.997 * *$ & 111.6 \\
\hline & Dongdan6 531 & 0.087 & -3.414 & 36.76 & $0.992 * *$ & 84.3 \\
\hline & Zeyu 8911 & 0.042 & -0.561 & -2.384 & $0.996 * *$ & 105.653 \\
\hline & Xianyu 335 & 0.138 & -5.175 & 50.87 & $0.998 * *$ & 103.238 \\
\hline & Xianyu 1331 & 0.071 & -1.405 & 5.822 & $0.976 * *$ & 172.268 \\
\hline & KWS2030 & 0.233 & -7.171 & 57.54 & $0.922 * *$ & 277.763 \\
\hline & Tieyuan 24 & 0.052 & -1.285 & 8.232 & $0.988 * *$ & 99.293 \\
\hline & Dongdan 1331 & 0.052 & -2.157 & 29.54 & $0.788 * *$ & 124.613 \\
\hline & Jiushenghe 2468 & 0.126 & -5.491 & 62.33 & $0.984 * *$ & 73.988 \\
\hline
\end{tabular}

3.3 Classification of maize variety grain breakage sensitivity to grain moisture content (BSW)

The center point of the BSW range was defined as the average integral value of the BSWs of all the tested varieties (Figure 3). The intermediate sensitivity range was defined as the $\pm 15 \%$ range from the center value. If the integral value of a cultivar fell within this range, the cultivar was identified as having intermediate breakage sensitivity; if the integral value of a variety fell below this range, it was identified as having weak breakage sensitivity and high resistance to breakage; if the integral value of a variety fell above this range, it was identified as having strong fragmentation sensitivity and low resistance to breakage. As shown in Figure3, 
twelve of the 28 tested varieties at Xinxiang Station had integral values ranging from 41.10 to 70.20 and were resistant to grain breakage: Dika 517, Xindan 65, Shandan 636, Xindan 58, Dongdan 913, Jidan 66, Zeyu 8911, Dika 653, Yudan 9953, Lidan 295, LA505, and Xindan 68. Eight of the 28 tested varieties had integral values ranging from 112.50 to 131.93 and displayed low resistance to grain breakage: Yufeng 303, Liaodan 575, Lianchuang 808 , Zhongkeyu 505, Nonghua 816, Jintong 152, Nonghua 5, and Lianchuang 825. The remaining eight varieties fell inside the intermediate BSW range (integral values between 71.59 and 97.46).

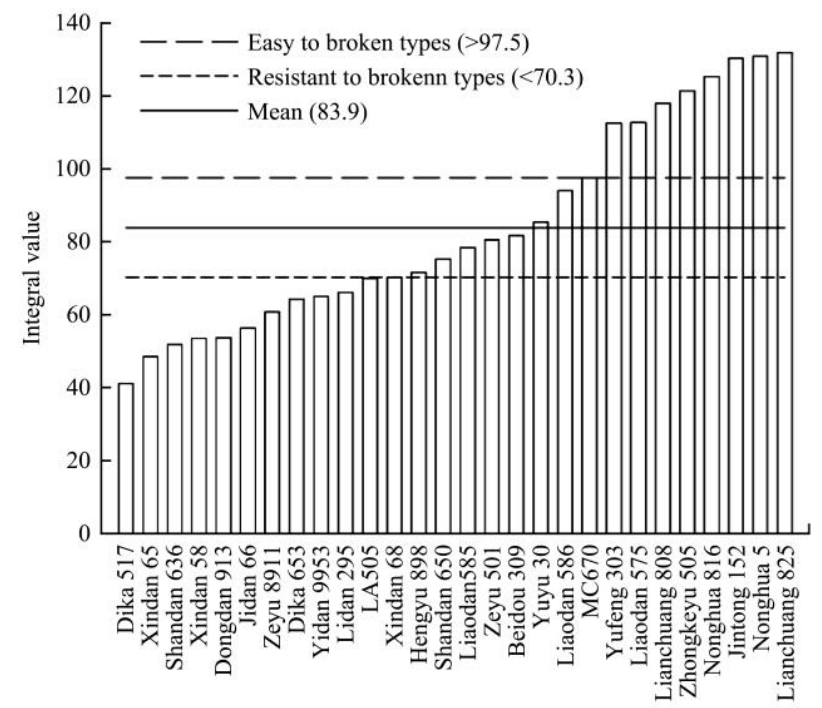

Figure 3 Classification of grain breakage sensitivity to grain moisture content (BSW) of different maize varieties tested at Xinxiang (integration method)

Figure 4 shows the classification results for the 18 varieties tested at Changji Station. Six varieties displayed weak breakage sensitivity and high breakage resistance (integral values between 73.99 and 102.12): Jiushenghe 2468, Dongdan 6531, Shandan 620, Jiuyu MO3, Tieyuan 24, and KWS9384. Four varieties were sensitive to breakage (integral values between 227.00 and 478.13): JP6145, KWS2030, Lianchuang 808, and Lianchuang 825. The remaining eight varieties fell in the intermediate range with integral values ranging from 103.24 to 222.45 . The integral value ranges for BSW used to classify the cultivars were quite different between the Xinxiang and Changji experimental stations.

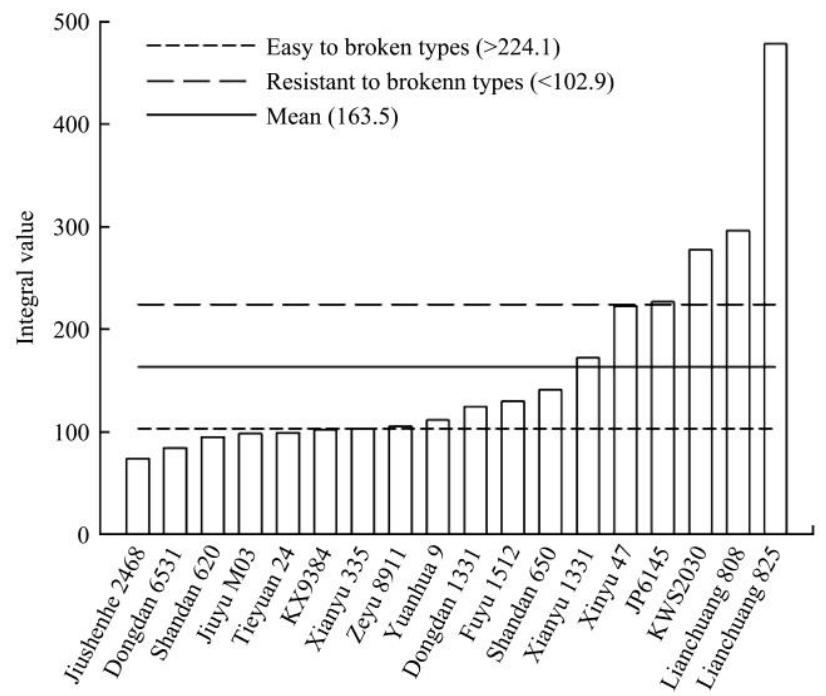

Figure 4 Classification of the BSW sensitivity of different maize varieties tested at Changji Station (integration method)
Zeyu 8911, Shaandan 650, Lianchuang 825, and Lianchuang 808 were the only varieties planted at both stations. Among these, Lianchuang 825 and Lianchuang 808 were classified as easily broken varieties, whereas Shaandan 650 was classified as having intermediate sensitivity. Zeyu 8911 was classified as highly resistant to breakage at Xinxiang Station but as intermediate at Changji Station.

\subsection{Comparison of breakage sensitivity classification by the integration and cumulative deviation methods}

The cumulative mean deviation method for breakage sensitivity classification proposed by Zhang ${ }^{[22]}$ expresses the breakage sensitivity of each variety by calculating the grain breakage rate of each variety under the measured grain moisture content and the total theoretical breakage rate of all tested varieties. This method was also based on the quadratic curve fitting of moisture content and breakage rate. The smaller the cumulative mean deviation, the better the result. The weaker the BSW, the more resistant a variety is to breakage. BSW was calculated by the cumulative mean deviation method as follows:

$$
\text { Breakage sensitivity }=\sum_{i=1}^{n} y_{i}-y_{i}^{\prime}
$$

where, $n$ is the total number of harvests; $i$ is the $i$-th harvest; $y_{i}$ is the actual grain breakage rate of the $i$-th harvest, and $y_{i}^{\prime}$ is the theoretical grain breakage rate of the $i$-th harvest.

In this study, the center point of the breakage sensitivity range was defined as the average value of the cumulative mean deviation. The intermediate sensitivity interval was defined as the $\pm 15 \%$ range from the center value. If the cumulative mean deviation of a variety falls within this interval, the various displays intermediate breakage sensitivity. If the value falls below this interval, the various displays weak breakage sensitivity and high resistance to breakage. If the value falls above the interval, the various displays strong fragmentation sensitivity and low resistance to breakage. The results of BSW classification by the cumulative mean deviation method for maize varieties at the Xinxiang and Changji stations are shown in Figure 5 and Figure 6.

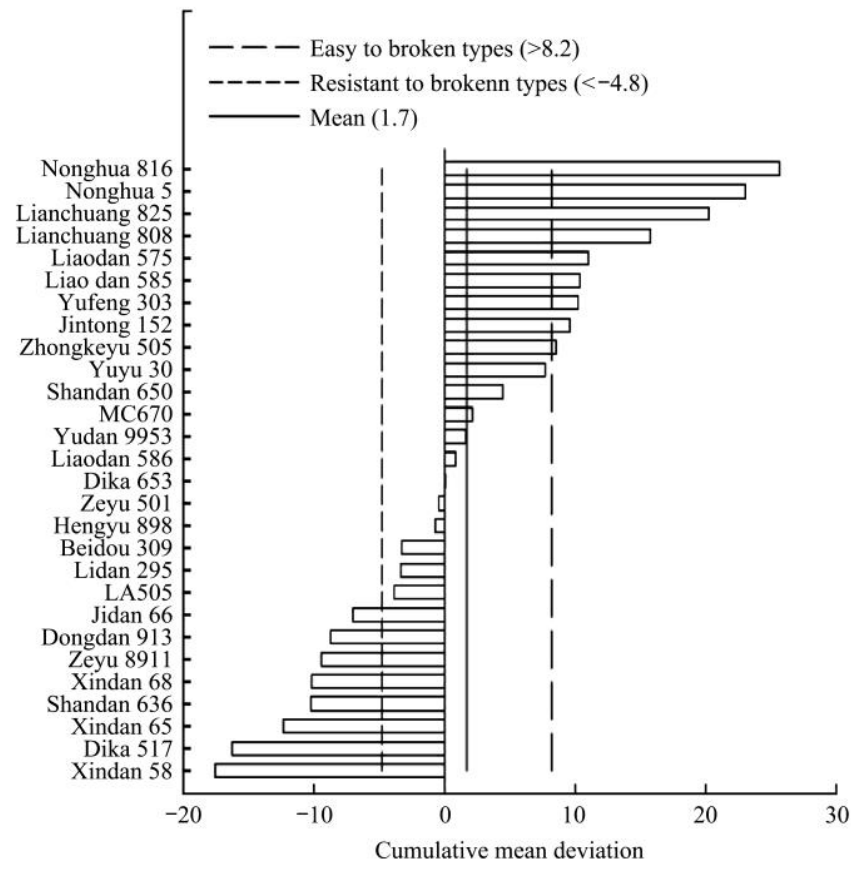

Figure 5 Classification of the breakage sensitivity of maize varieties tested at the Xinxiang Station (cumulative mean deviation method) 


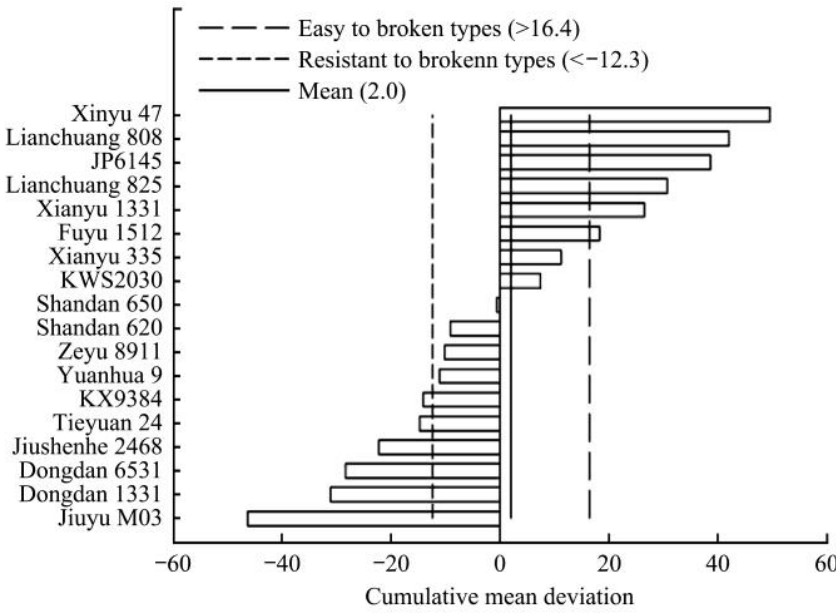

Figure 6 Classification of the breakage sensitivity of maize varieties tested at the Changji Station (cumulative mean deviation method)

At Xinxiang Station, the two different breakage sensitivity classification methods identified the same eight varieties as grain breakage sensitive, the same seven varieties as having intermediate sensitivity, and the same eight varieties as breakage resistance. The two methods identified one variety that was a cross between the breakage-sensitive type and the intermediate type, four that crossed between the breakage-resistant type and the intermediate type, and none that were crosses between the breakage-sensitive type and the breakage-resistant type. The overall agreement between the two methods was $82.14 \%$.

At Changji Station, the two different breakage sensitivity classification methods identified the same three varieties as grain breakage sensitive, the same four varieties as having intermediate sensitivity, and the same five varieties as breakage resistance.

The two methods identified four varieties that were screened between the breakage-sensitive type and the intermediate type, two that crossed between the breakage-resistant type and the intermediate type, and none that were crosses between the breakage-sensitive type and the breakage-resistant type. The overall agreement between the two methods was $66.67 \%$.

\section{Discussion}

\subsection{Comparison of the maize moisture content during harvest} in China and the U.S.

In China, the latitudinal span of the maize-growing region is larger than in the U.S. and there are more planting patterns. This results in a large variation in moisture content in the different maize-growing regions at harvest. The U.S. "Corn Belt" is mainly situated between $38^{\circ} \mathrm{N}-43^{\circ} \mathrm{N}$, which is similar in terms of environmental conditions to the north spring maize region in China. From 2011 to 2016, our research group investigated the moisture content of 2450 harvested maize grain samples in $\mathrm{China}^{[2]}$, finding an average moisture content of $26.65 \%$. In contrast, the average moisture content of maize at harvest in the U.S. was $15.7 \%$ in 2015 , $16.1 \%$ in 2016 , and $16.6 \%$ in $2017^{[27]}$, which is much lower than that in China. This difference in moisture content at harvest suggests that more consideration should be given to variations in breakage rate due to different moisture content when evaluating maize grain breakage resistance in China.

\subsection{Effects of grain type and weight on BSW.}

At Xinxiang station, total percentages of resistance to breakage type by classification were $42.9 \%, 42.1 \%$ and $50.0 \%$ for horse-toothed, half horse-toothed and hard maize, respectively, while at Changji station, only $16.7 \%$ for Horse-toothed maize are resistance to breakage (Table 5). Compared with the horse-toothed and the half horse-toothed maize, the hard maize did not show obvious resistance to breakage.

Table 5 Percentage of breakage sensitive of Horse-toothed, Half horse-toothed and Hard maize

\begin{tabular}{|c|c|c|c|c|c|}
\hline \multirow{2}{*}{ Site } & \multirow{2}{*}{ Kernel type } & \multirow{2}{*}{ Sample size } & \multicolumn{3}{|c|}{ Breakage sensitivity/\% } \\
\hline & & & Resistance & Intermediate & Sensitivity \\
\hline \multirow{3}{*}{ Xinxiang } & Horse-toothed & 7 & 42.9 & 42.9 & 14.3 \\
\hline & Half horse-toothed & 19 & 42.1 & 21.1 & 36.8 \\
\hline & Hard & 2 & 50.0 & 50.0 & 0.0 \\
\hline \multirow{3}{*}{ Changji } & Horse-toothed & 6 & 16.7 & 66.7 & 16.7 \\
\hline & Half horse-toothed & 9 & 44.4 & 33.3 & 22.2 \\
\hline & Hard & 3 & 33.3 & 33.3 & 33.3 \\
\hline
\end{tabular}

100-kernels weight was significantly positively correlated with breakage sensitivity (Table 6). At Xinxiang station, the resistance and intermediate breakage sensitivity were significantly different at $p=0.05$, with means of $36.93 \mathrm{~g}$ and $41.35 \mathrm{~g}$, respectively. This is

Table 6 100-kernels weight of different breakage sensitivity types (14\% grain moisture content)

\begin{tabular}{clccc}
\hline \multirow{2}{*}{ Site } & \multirow{2}{*}{$\begin{array}{c}\text { Breakage } \\
\text { sensitivity }\end{array}$} & \multicolumn{3}{c}{ 100-kernels weight/g } \\
\cline { 3 - 5 } & Resistance & 44.45 & 30.59 & $36.93 \mathrm{a}$ \\
\hline \multirow{3}{*}{ Xinxiang } & Intermediate & 45.48 & 34.23 & $41.35 \mathrm{~b}$ \\
& Low resistance & 48.63 & 38.98 & $44.63 \mathrm{~b}$ \\
\hline \multirow{3}{*}{ Changji } & Resistance & 35.71 & 29.17 & $32.61 \mathrm{a}$ \\
& Intermediate & 42.95 & 25.20 & $33.75 \mathrm{a}$ \\
& Low resistance & 40.38 & 32.95 & $37.01 \mathrm{a}$ \\
\hline
\end{tabular}

Note: Values followed by the same lowercase letter in the same column are not significantly different at $p \leq 0.05$, according to the LSD test. different from the research results of Vyn et al. ${ }^{[11]}$ The difference is thought to be due to different testing methods. In addition, the breakage sensitivity of the varieties was also affected by the growth environment, grain shape and the maize cob mechanical strength ${ }^{[7,11]}$.

\subsection{Comparison of test results and field production data}

From 2014-2019, the moisture content and breakage rate of grain harvested from maize varieties Lianchuang825 (LC825), Lianchuang808 (LC808), Shandan650 (SD650), and Zeyu8911 (ZY8911) had been investigated. The site, year, and harvester model conditions are shown in Table 7.

The moisture content of the four varieties were $26.90 \%$, $26.37 \%, 25.95 \%$, and $25.03 \%$ (Table 8), respectively; the coefficients of variation were $17.23 \%, 16.42 \%, 18.38 \%$, and $19.41 \%$; the breakage rates were $12.11 \%, 10.42 \%, 7.53 \%$, and $5.20 \%$; and the coefficients of variation were $41.31 \%, 50.13 \%$, $61.55 \%$, and $50.72 \%$. There was no significant difference in the moisture content of the four varieties, and the breakage rate of LC825 and LC808 were both significantly higher than that of 
SD650 and ZY8911. This is consistent with the results obtained by the integral method, which shows that the evaluation of grain breakage resistance by this method is highly consistent with actual production results.

Table 7 Location, variety, and year of mechanical grain harvest survey

\begin{tabular}{|c|c|c|c|c|c|}
\hline Site & North latitude & East longitude & Maize variety & Harvest year & Harvester model \\
\hline Suzhou, AH & $33^{\circ} 39^{\prime}$ & $116^{\circ} 57^{\prime}$ & LC808, LC825, SD650 & $2014,2017,2019$ & LovolGuShen GE60 \\
\hline Guoyang, $\mathrm{AH}$ & $33^{\circ} 30^{\prime}$ & $116^{\circ} 13^{\prime}$ & LC825, SD650 & 2017 & CASE 4088 \\
\hline Miyun, BJ & $40^{\circ} 23^{\prime}$ & $116^{\circ} 50^{\prime}$ & LC808, & 2014-2016 & John Deere R230 \\
\hline Wuwei, GS & $37^{\circ} 40^{\prime}$ & $102^{\circ} 51^{\prime}$ & LC808, LC825 & $2015,2017,2018$ & John Deere C110/R230 \\
\hline Jiuquan, GS & $39^{\circ} 41^{\prime}$ & $98^{\circ} 42^{\prime}$ & LC808, LC825, SD650 & $2014,2017,2018$ & LovolGuShen GE60 \\
\hline Handan, HB & $36^{\circ} 37^{\prime}$ & $114^{\circ} 32^{\prime}$ & ZY8911 & 2018 & LovolGuShen GE60 \\
\hline Cixian, HB & $36^{\circ} 22^{\prime}$ & $114^{\circ} 22^{\prime}$ & LC808, ZY8911 & 2014,2015 & Dongfeng 2000 \\
\hline Chengan, HB & $36^{\circ} 26^{\prime}$ & $114^{\circ} 40^{\prime}$ & LC808, LC825, SD650, ZY8911 & 2014,2017 & ZoomlionGuwang TB60 \\
\hline Yongnian, HB & $36^{\circ} 45^{\prime}$ & $114^{\circ} 33^{\prime}$ & ZY8911 & 2017 & LovolGuShen GE50 \\
\hline Shangshui, HN & $33^{\circ} 32^{\prime}$ & $114^{\circ} 37^{\prime}$ & LC808, LC825, SD650, ZY8911 & 2017 & LovolGuShen GE50 \\
\hline Shangqiu, HN & $34^{\circ} 25^{\prime}$ & $115^{\circ} 39^{\prime}$ & LC808, LC825, SD650, ZY8911 & 2017 & LovolGuShen GE50 \\
\hline Nanyang, HN & $33^{\circ} 00^{\prime}$ & $112^{\circ} 32^{\prime}$ & LC808 & 2015 & LovolGuShen GE50 \\
\hline Linying, HN & $33^{\circ} 52^{\prime}$ & $113^{\circ} 50^{\prime}$ & LC808, LC825 & 2017 & LovolGuShen GE60 \\
\hline Lankao, HN & $34^{\circ} 57^{\prime}$ & $114^{\circ} 51^{\prime}$ & LC808, LC825, SD650, ZY8911 & 2017 & LovolGuShen GE60 \\
\hline Jiaozuo, HN & $35^{\circ} 07^{\prime}$ & $113^{\circ} 21^{\prime}$ & LC808 & 2015 & LovolGuShen GE50 \\
\hline Huaxian, HN & $35^{\circ} 37^{\prime}$ & $114^{\circ} 42^{\prime}$ & LC808, LC825, SD650, ZY8911 & 2017 & LovolGuShen GE60 \\
\hline Luoyang, HN & $34^{\circ} 37^{\prime}$ & $112^{\circ} 27^{\prime}$ & ZY8911 & 2018 & ZoomlionGuwang TB60 \\
\hline Xinxiang, HN & $35^{\circ} 18^{\prime}$ & $113^{\circ} 55^{\prime}$ & LC808, LC825, SD650, ZY8911 & $2014,2015,2017$ & LovolGuShen GE50 \\
\hline Zhaozhou, HLJ & $45^{\circ} 42^{\prime}$ & $125^{\circ} 15^{\prime}$ & LC 808 & 2014 & John Deere C110 \\
\hline Shuangcheng, HLJ & $45^{\circ} 23^{\prime}$ & $126^{\circ} 19^{\prime}$ & LC808 & 2015 & John Deere C110 \\
\hline Longjiang, HLJ & $47^{\circ} 20^{\prime}$ & $123^{\circ} 12^{\prime}$ & LC808 & 2014,2015 & LovolGuShen GK120 \\
\hline Daqing, HLJ & $46^{\circ} 08^{\prime}$ & $124^{\circ} 26^{\prime}$ & LC808 & 2015 & John Deere C110 \\
\hline Yushu, JL & $44^{\circ} 59^{\prime}$ & $126^{\circ} 19^{\prime}$ & LC808 & 2015 & CASE 4088 \\
\hline Yancheng, JS & $33^{\circ} 21^{\prime}$ & $120^{\circ} 10^{\prime}$ & LC808, LC825, SD650 & 2015,2017 & LovolGuShen GE60 \\
\hline Lianyungang, JS & $34^{\circ} 37^{\prime}$ & $119^{\circ} 12^{\prime}$ & LC808, LC825, SD650 & 2017 & LovolGuShen GE60 \\
\hline Tieling, LN & $42^{\circ} 21^{\prime}$ & $123^{\circ} 37^{\prime}$ & LC808, ZY8911 & 2015, 2018, 2019 & John Deere C110 \\
\hline Tongliao, IM & $43^{\circ} 34^{\prime}$ & $121^{\circ} 12^{\prime}$ & LC808 & 2015 & John Deere C110 \\
\hline Chifeng, IM & $42^{\circ} 17^{\prime}$ & $118^{\circ} 56^{\prime}$ & LC808, ZY8911 & 2015,2018 & Dongfeng 2000 \\
\hline Salaqi, IM & $40^{\circ} 34^{\prime}$ & $110^{\circ} 31^{\prime}$ & SD650 & 2017 & John Deere R230 \\
\hline Laizhou, SD & $37^{\circ} 10^{\prime}$ & $119^{\circ} 56^{\prime}$ & ZY8911 & 2018 & LovolGuShen GE60 \\
\hline Dezhou, SD & $37^{\circ} 26^{\prime}$ & $116^{\circ} 21^{\prime}$ & ZY8911 & 2018 & LovolGuShen GE60 \\
\hline Renping, SD & $36^{\circ} 30^{\prime}$ & $116^{\circ} 19^{\prime}$ & SD650, ZY8911 & 2017,2018 & LovolGuShen GE50 \\
\hline Xinzhou, SX & $38^{\circ} 25^{\prime}$ & $112^{\circ} 44^{\prime}$ & LC825, SD650, ZY8911 & 2018,2019 & ZoomlionGuwang TB60 \\
\hline Yulin, SAX & $38^{\circ} 17^{\prime}$ & $109^{\circ} 44^{\prime}$ & SD650 & 2017 & LovolGuShen GE50 \\
\hline Qitai, SJ & $43^{\circ} 54^{\prime}$ & $89^{\circ} 46^{\prime}$ & LC808, LC825, SD650, ZY8911 & 2014-2018 & John Deere C110/W210 \\
\hline Changji, SJ & $44^{\circ} 01^{\prime}$ & $87^{\circ} 19^{\prime}$ & LC808, LC825, SD650, ZY8911 & 2018 & John Deere W210 \\
\hline Xinyuan, SJ & $43^{\circ} 30^{\prime}$ & $83^{\circ} 17^{\prime}$ & LC808, SD650, ZY8911 & 2015,2017 & Dongfeng 2000 \\
\hline
\end{tabular}

Note: AH, Anhui; BJ, Beijing; GS, Gansu; HB, Hebei; HN, Henan; HLJ, Heilongjiang; JL, Jilin; JS, Jiangsu; LN, Liaoning; IM, Inner Mongol; SD, Shandong; SX, Shanxi; SAX, Shaanxi; and SJ, Xinjiang.

Table 8 Harvested maize kernel moisture content and breakage rate during 2014-2019

\begin{tabular}{|c|c|c|c|c|c|c|c|c|c|}
\hline \multirow{2}{*}{ Varieties } & \multicolumn{4}{|c|}{ Grain moisture content $/ \%$} & \multicolumn{4}{|c|}{ Grain breakage rate $/ \%$} & \multirow{2}{*}{ Coun } \\
\hline & Max & Min & Mean & $\mathrm{CV} / \%$ & Max & Min & Mean & $\mathrm{CV} / \%$ & \\
\hline LC825 & 34.53 & 16.90 & $26.90^{\mathrm{a}}$ & 17.23 & 23.07 & 0.43 & $12.11^{\mathrm{a}}$ & 41.31 & 21 \\
\hline LC808 & 33.80 & 15.90 & $26.37^{\mathrm{a}}$ & 16.42 & 23.42 & 0.57 & $10.42^{\mathrm{a}}$ & 50.13 & 50 \\
\hline SD650 & 33.87 & 17.33 & $25.95^{\mathrm{a}}$ & 18.38 & 19.20 & 0.12 & $7.53^{\mathrm{b}}$ & 61.55 & 27 \\
\hline ZY8911 & 32.60 & 17.10 & $25.03^{\mathrm{a}}$ & 19.41 & 11.44 & 0.12 & $5.20^{\mathrm{c}}$ & 50.72 & 35 \\
\hline
\end{tabular}




\section{Conclusions}

Field mechanical harvesting and the quadratic curve based integration method (BSW) can be used to evaluate the grain breakage sensitivity and breakage resistance of different maize varieties. In this study, twelve and six breakage-resistant varieties were screened by this method in Xinxiang and Changji experimental sites. The results provide a basis for the further selection of suitable varieties for mechanical grain harvesting and further research on breakage resistance mechanisms of different varieties.

\section{Acknowledgements}

This work was financially supported by the National Key Research and Development Program of China (2016YFD0300110, 2016YFD0300101), the National Natural Science Foundation of China (31371575), the China Agriculture Research System (CARS-02-25), and the Agricultural Science and Technology Innovation Project of the Chinese Academy of Agricultural Science.

\section{[References]}

[1] Li S K. Factors affecting the quality of maize grain mechanical harvest and the development trend of harvest technology. Journal of ShiheziUniversity (Natural Science), 2017; 35: 265-272. (in Chinese)

[2] Li S K, Wang K R, Xie R Z, Li L L, Ming B, Hou P, et al. Grain breakage rate of maize by mechanical harvesting in China. Crops, 2017; 2: 76-80, 173. (in Chinese)

[3] Yang L, Cui T, Qu Z, Li K H, Yin X W, Han D D, et al. Development and application of mechanized maize harvesters. Int J Agric \& Biol Eng, 2016; 9(3): 15-28.

[4] Chai Z W, Wang K R, Guo Y Q, Xie R Z, Li L L, Ming B, et al. Current status of maize mechanical grain harvesting and its relationship with grain moisture content. Scientia Agricultura Sincia, 2017; 50(11): 2036-2043. (in Chinese)

[5] Yi K C, Zhu D W, Zhang X W, Yao Z H, Liu Z. Effect of moisture content on corn grain harvesting mechanization. Journal of Chinese Agricultural Mechanization, 2016; 37: 78-80.

[6] Moentono M D, Darrah L L, Zuber M S, Krayse G F. Effects of selection for stalk strength on the response to plant density and level of nitrogen application in maize microform. Hawaii International Conference on System Sciences, 1984; 29: 431-452.

[7] Plett S. Corn kernel breakage as a function of grain moisture at harvest in a prairie environment. Canada Journal Plant Science, 1994; 74(3): 543-544.

[8] Bingen T R. Trends in the process technology of grain crop harvesting. Agritechnica, 2007; 62: 388-389.

[9] Bauer P J, Carter P R. Effect of seeding date plant density, moisture availability and soil nitrogen fertility on maize kernel breakage susceptibility. Crop Science, 1986; 26(6): 1220-1226.
[10] Li L L, Xue J, Xie R Z, Wang K R, Ming B, Hou P, et al. Effects of grain moisture content on mechanical grain harvesting quality of summer maize. Acta AgronomicaSinica, 2018; 12: 1747-1754.

[11] Vyn T J, Moes J. Breakage susceptibility of corn kernels in relation to crop management under long growing season conditions. Agronomy Journal, 1988; 80(6): 915-920.

[12] Greenaway WT, A wheat hardness index. Cereal Sci Today, 1969; 14 4-7.

[13] Blandino M, Mancini M C, Peila A, Rolle L, Vanara F, Reyneri A Determination of maize kernel hardness: comparison of different laboratory tests to predict dry-milling performance. Journal of the Science of Food \& Agriculture, 2010; 90(11): 1870-1878.

[14] Fox G, Manley M. Hardness methods for testing maize kernels. Journal Agricultural Food Chemistry, 2009; 57: 5647-5657.

[15] Lee K M, Bean S R, Alavi S, Herrman T J, Waniska R D. Physical and biochemical properties of maize hardness and extrudates of selected hybrids. Journal of Agricultural and Food Chemistry, 2006; 54: 4260-4269.

[16] Robutti J L, Borras F S, Eyherabide G H. Zein composition of mechanically separated coarse and fine portions of maize kernels. Cereal Chemistry, 1997; 74: 75-78.

[17] Paulsen M R, Hill L D, White D G, Sprague G F. Breakage susceptibility of corn-belt genotypes. Transactions of the ASAE, 1983; 26(6): 1830-1836.

[18] Mensah J K, Herum F L, Blaisdell J L, Stevens K K. Effect of drying conditions on impact shear resistance of selected corn varieties. Transactions of the ASAE, 1981; 24(6): 1568-1572.

[19] Johnson D Q, Russell W A. Genetic variability and relationships of physical grain-quality traits in the BSSS population of maize. Crop Science, 1982; 22(4): 805-809.

[20] AACC (American Association of Cereal Chemists). Approved methods of AACC. Method 55-20, Approved November 1981. The Association, St. Paul, MN.

[21] Zhu X W, Cao C W. Study on relationship of stress cracks and breakage susceptibility of corn dried in heated air. Transactions of the Chinese Society of Agricultural Machinery, 1998; 29: 60-72. (in Chinese)

[22] Paulsen M R, Nave W R. Corn damage from conventional and rotary combines. Transactions of the ASAE, 1980; 23(5): 1100-1116.

[23] Dutta P K. Effects of grain moisture, drying methods, and variety on breakage susceptibility of shelled corns as measured by the Wisconsin Breakage Tester. PhD dissertation, Iowa State University, 1986; 221p

[24] Miller B S, Hughes J W, Rousser R, Booth G D. Effects of modification of a model CK2 stein breakage tester on corn breakage susceptibility. Cereal Chemisty, 1981; 58(3): 201-203.

[25] Wang K R, Li L L, Guo Y Q, Fan P P, Cai Z W, Hou P, et al. Effects of different mechanical operation on maize grain harvest quality. Journal of Maize Sciences, 2016; 24: 114-116. (in Chinese)

[26] Zhang W X, Wang K R, Xie R Z, Hou P, Ming B, Liu C W, et al Relationship between maize grain broken rate and moisture content as well as the differences among cultivars. Journal of Maize Sciences, 2018; 26: 74-78. (in Chinese)

[27] U. S. Grain Council. Cornharvestqualityreport (2017-2018). U. S. Grain Council. 2018. https://grains.org/corn_report/ corn-harvest-quality-report-2017-2018. Accessd on [2020-01-02]. 